\title{
Isolation of Phosphate Solubilizing Bacteria and Fungi from Rhizospheres soil from Banana Plants and its Effect on the Growth of Amaranthus cruentus L.
}

\author{
Reena $^{1}$, T. Dhanya ${ }^{2}$, H. Deepthi ${ }^{3}$, M.S and Pravitha ${ }^{4}$ D.Lecturer ${ }^{5}$ \\ Department of Microbiology Malanakara Catholic College Mariagiri, Kaliakkavilai- 629053.
}

\begin{abstract}
Nutrient management is one of the most important factors in successful cultivation of plants. Biofertilizers can affect the quality and quantity of crop. Low phosphate solubility is one of the most important factors limiting the plant growth in various soils. Many microorganisms can enhance phosphate solubility, but little is known about the magnitude of their phosphorus solubilizing ability. The native populations of phosphate-solubilizing bacteria and fungi were studied in different rhizospheres soil samples obtained from banana plant and its effect on spinach plant (Amaranthus cruentus L.) in order to compare the results. The present study focuses on the phosphate-solubilizing capacity of bacteria and fungi in rhizospheres soil samples obtained from banana plant, revealing the dominance of Aspergillus species (234.12 $\mathrm{mm})$ as major phosphate solubilizers, along with Bacillus subtilis (160.82 $\mathrm{mm}$ ) followed by Pseudomonas aeruginosa 126.11, Penicillium sp., 99.02 and Micrococcus sp., 89. 4. In the present study potent solubilizers were identified as A. niger and B. subtilis. Hence an attempt was made to optimize the phosphate solubilization of the potential solubilizers at different $\mathrm{pH}$ with temperature. It is found out that both bacteria and fungi showed maximum phosphate solubilization at $\mathrm{pH} 3.0$ with its specific temperature at $28^{\circ} \mathrm{C}$ and $37^{\circ} \mathrm{C}$.
\end{abstract}

Keywords: Aspergillus, Bacillus, phosphates, Amaranthus cruentus, rhizospheres soil

\section{Introduction}

Phosphorus is one of the major limiting factors for crop production on many tropical and subtropical soils. It is therefore necessary to identify and incorporate efficient strains of phosphate solubilizing microorganisms in to cropping systems (Fankem et al., 2006). For sustained agricultural production, use of efficient fertilizer to maintain the soil and plant quality is critical. The application of organic fertilizer has been practiced for more than thousand years in many countries since it provides essential nutrients to plants, improves soil structure, helps in the moisture retaining capacity in various soils and increases microbial activities (Chen et al., 2006). In developing countries like India the stress on agriculture is increasing day by day. The land under farming is decreasing and this has posed an extra burden on agriculture. Therefore the land available for agriculture should be utilized economically (Dubey and Maheshwari, 2000). Later, Gyaneshwar et al., 2002 proposed the most of the agricultural lands are deprived of one or more minerals required for the growth and development of plants. Inorder to provide these minerals we are depending upon chemical fertilizers. Such chemical fertilizers pose health hazards and pollution problem in soil besides these are quite expensive. Moreover the usage of chemical fertilizers will kill the normal flora of the soil beneficial microorganisms (Whitelaw, 2000). Very recently, Padmavathi and Usha, 2012 published phosphorus is a plant macronutrient that plays a significant role in plant metabolism, ultimately reflected on crop yields.

Agricultural and animal wastes are the major raw materials for organic fertilizers that are produced by the process of composting (Asal, 2010). The advantage of using these kinds of organic fertilizers is they provide balanced nutrient supply, facilitate the growth of beneficial microorganisms and help to suppress certain plant diseases and soil borne diseases (Jedidi et al., 2004). Thus, it has reduced their usage and paved way for the use of inorganic/chemical fertilizers. Asia is the world's largest chemical fertilizer consuming continent of about $40 \%$ of the total global production. Even in an agricultural nation like India the use of inorganic and chemically synthesized fertilizer is in large proportion (El-komy, 2005). Though organic fertilizers generally contain lower concentrations and release nutrients at a slower rate compared to synthetic fertilizers, organic fertilizers offer a healthier alternative to chemical fertilizers (De Souza et al., 2000; Abdalla and Omar, 2001; Afzal et al., 2005; Afzal and Ashgari, 2008). Therefore, very few amount of works has done in the similar kind of research, since the present work have been designed the following objectives such as to isolate and identified the phosphate solubilizing microorganism. Then to determined the phosphate solubilizing efficiency of isolated microorganisms finally to established the effect of the $\mathrm{pH}$ and temperature on the phosphate solubilization efficiency of selected species 


\section{Materials and methods}

Soil analysis

The rhizosphere soil samples were collected from 4 different betel cultivating areas: Murunadu, Beerur (with samples from 2 different Beerur locations), and Bangalore regions of Karnataka, India. Soil samples were collected from 10 randomized banana plant rhizospheres in order to obtain as to a large extent possible unpredictabile in the microorganisms for a qualified analysis. To sustain consistency, the soils were in use from within $20 \mathrm{~cm}$ locality of the plant and from depths of $6-8 \mathrm{~cm}$ from the surface during the months of November and December. The soil samples were desiccated, compacted and passed through a 2 -mm sieve before being mixed into a single merged sample. These soil samples were then analyzed and the characteristics of the soils were tabulated.

\section{Isolation of Phosphate Solubilizing Microorganisms}

The collected soil samples were serially diluted using sterile water blanks and plated on Pikovskaya's Agar medium. The plates were incubated at $28^{0} \mathrm{C}$ for 3-5 days. After incubation the phosphate solubilizing microorganisms were selected based on the zone of clearing around the colonies. The isolated phosphate solubilizing fungi and bacteria were purified by repeated culturing and maintained on Potato Dextrose Agar and Nutrient Agar slants at $4^{0} \mathrm{C}$.

\section{Identification of bacterial isolates}

The isolated species were identified using with some modifications also done by Nopparat et al. (2007) based on characters such as morphology, staining reactions, nutritional, cultural characteristics , physiology and biochemical test results for specific metabolic end products. Also following criteria based identification conformed viz., Gram staining, Motility Test, Starch hydrolysis, Gelatin hydrolysis, Lipid hydrolysis, Carbohydrate fermentation test, Urea hydrolysis test, Hydrogen Sulphide Production test, Indole production test, Methyl Red test, Voges-Proskaeur test, Citrate utilization test, Oxidase test and Catalase test (Dubey and Maheshwari, 2000) .

\section{Isolation of rhizospheric microflora}

From each soil sample, $1 \mathrm{~g}$ of soil was suspended in a $9-\mathrm{mL}$ blank and serially diluted. The dilutions were plated on Pikovskaya's (PVK) medium in order to isolate the PSB and PSF (17-19). Those colonies surrounded with a halo zone were transferred to PVK medium 3 times in order to maintain the purity of the culture.

\section{Isolation of PSMs}

Phosphate solubilization on PVK medium was examined by growing the different isolates on PVK medium substituted with TCP, KHP, and RP. The concentrations of TCP, KHP, and RP used in the media were varied by taking $2.5 \mathrm{~g} \mathrm{~L}-1,5.0 \mathrm{~g} \mathrm{~L}-1$, and $7.5 \mathrm{~g} \mathrm{~L}-1$ in the basal PVK medium (Chailharn et al., 2008). The plates were inoculated using point inoculation and incubated at $28{ }^{\circ} \mathrm{C}$ for 3 days and 5 days for bacteria and fungi, respectively. The solubility of phosphate was observed as a zone of clearance with a diameter that was measured in millimeters and taken in triplicate (9). The microbial phosphorus solubilization trait was analyzed by determining the P-solubilization efficiency (PSE).

$\mathrm{PSE}=$ diameter of entire colony/diameter of clearing zone $\times 100$

The efficient P-solubilizing bacterial species were then further identified (Suliasih and Widawati, 2005).

\section{Measurement of pH and Titrable acidity}

Initially culture filtrates were centrifuged at 1000rpm for 10mts. Five milliliter of supernatant was added with a few drops of Phenopththalein indicator and titrated against $0.01 \mathrm{~N} \mathrm{NaOH}$. The titrable acidity was experessed as $\mathrm{ml}$ of $0.01 \mathrm{~N} \mathrm{Na} \mathrm{OH}$ consumed per $5.0 \mathrm{ml}$ of culture filtrate.

\section{Statistical Analysis}

The data obtained were statistically analyzed for Analysis Of Variance (ANOVA) for significance at $\mathrm{P}$ $\leq 0.05$ with the ORIGIN soft ware program (28).

\section{Results}

Table -1 stands for identification criteria of Phosphate Solubilizing Bacteria (PSB) from banana rhizospheres soil. Mainly three different kinds of PSB isolated designed named as well as isolated code was $\mathrm{PSB}_{1}, \mathrm{PSB}_{2}, \mathrm{PSB}_{3}$. Similarly two broad spectrum of isolated PSF were identified such as $\mathrm{PSF}_{1}$ and $\mathrm{PSF}_{2}$ accompanied with its specific microscopic observation (Table-2). 
Table 1: Identification of isolated phosphate solubilizing Bacteria

\begin{tabular}{|l|c|c|c|}
\hline \multirow{2}{*}{ Characteristics } & \multicolumn{3}{|c|}{ Isolated code } \\
\cline { 2 - 4 } & PSB $_{\mathbf{1}}$ & PSB $_{\mathbf{2}}$ & PSB $_{\mathbf{3}}$ \\
\hline \multirow{2}{*}{ Gram staining } & Rod & Cocci & Rod \\
& + & - & - \\
\hline Motility & + & - & + \\
\hline Starch Hydrolysis & - & - & + \\
\hline Lipid Hydrolysis & + & - & + \\
\hline Gelatin Hydrolysis & + & - & + \\
\hline Carbohydrate Fermentation (Lactose) & - & - & - \\
\hline H 2 S production & - & - & - \\
\hline Indole production Test & - & - & + \\
\hline Methyl Red test & - & + & - \\
\hline Voges proskauer test & - & + & - \\
\hline Citrate test & + & - & - \\
\hline Urease test & - & - & + \\
\hline Catalase test & + & + & - \\
\hline Oxidase test & & & + \\
\hline
\end{tabular}

(+) positive

$(-)$ negative

Table 2: Identification of Isolated Phosphate Solubilizing Fungi (PSF)

\begin{tabular}{|l|l|l|}
\hline Isolate code & Colony Morphology & Microscopic observation \\
\hline $\mathrm{PSF}_{1}$ & Blackish and fluffy & $\begin{array}{l}\text { Septate mycelium, hyphae with, } \\
\text { elliptical vesicle bearing chains of } \\
\text { conidia }\end{array}$ \\
\hline $\mathrm{PSF}_{2}$ & Blue green and velvetty & $\begin{array}{l}\text { Septate mycelium, hyphae bearing } \\
\text { conidiospores had brush like } \\
\text { appearance. }\end{array}$ \\
\hline
\end{tabular}

Table-3: Phosphate solubilization efficiency of selected Microorganisms on Pikovskaya's Agar plate

\begin{tabular}{|l|c|c|c|}
\hline \multirow{2}{*}{ Microorganism } & \multicolumn{3}{|c|}{$\begin{array}{c}\text { Solubilization Efficiency (Average zone of } \\
\text { clearence) }\end{array}$} \\
\cline { 2 - 4 } & $\mathbf{2}^{\text {nd }}$ day & $\mathbf{4}^{\text {th }}$ day & $\mathbf{6}^{\text {th }}$ day \\
\hline Bacillus subtilis & 112.22 & 160.56 & 160.82 \\
\hline Micrococcus sp. & 62.60 & 89.04 & 89.04 \\
\hline Pseudomonas aeruginosa & 108.04 & 120.36 & 126.11 \\
\hline Aspergillus niger & 80.12 & 216.26 & 234.12 \\
\hline Penicillium sp. & 98.40 & 98.42 & 99.02 \\
\hline
\end{tabular}

The present study focuses on the phosphate-solubilizing capacity of bacteria and fungi in rhizospheric soil samples obtained from banana plant, revealing the dominance of Aspergillus species $(234.12 \mathrm{~mm}$ ) as major phosphate solubilizers, along with Bacillus subtilis $(160.82 \mathrm{~mm}$ ) followed by P. aeruginosa 126.11 , Penicillium sp., 99.02 and Micrococcus sp., 89.4 (Table-3).

Although maximum amount of phosphate solubilization occurred on sixth date of experiment accompanied with its responsible organisms of A. niger $(3.90 \mathrm{mg} / 25 \mathrm{ml})$ followed by Penicillium sp. (3.01 $\mathrm{mg} / 25 \mathrm{ml})$, B. subtilis $(2.61 \mathrm{mg} / 25 \mathrm{ml})$. While, the lowest amount of phosphate solubilization was noted on Micrococcus sp., (1.50 mg/25ml). In addition fourth day experiment expressed the Phosphate solubilization efficiency range from 1.40 to $3.70(\mathrm{mg} / 25 \mathrm{ml})$ observed the microorganism of Micrococcus sp. and A. niger respectively. Similar effect also been noted on initial date of second day of the experiment. Moreover, three se of experiment with two days interval clearly denotes the comparatively Phosphate solubilization effectively takes place in sixth day with fungi named as A. niger than the bacteria (Table-4). 
Table. 4 Quantitative Estimation of Phosphate solubilization in Pikovskaya's liquid medium

\begin{tabular}{|c|c|c|c|}
\hline \multirow{2}{*}{ Microorganism } & \multicolumn{3}{|c|}{ Available phosphate $(\mathbf{m g} / \mathbf{2 5 m l})$} \\
\cline { 2 - 4 } & $\mathbf{2}^{\text {nd }} \mathbf{d a y}$ & $\mathbf{4}^{\text {th }} \mathbf{d a y}$ & $\mathbf{6}^{\text {th }}$ day \\
\hline Uninoculated & 0.20 & 0.20 & 0.21 \\
\hline B. subtilis & 0.70 & 2.60 & 2.61 \\
\hline Micrococcus sp. & 0.40 & 1.40 & 1.50 \\
\hline P. aeruginosa & 0.50 & 2.40 & 2.40 \\
\hline A. niger & 0.60 & 3.70 & 3.90 \\
\hline Penicillium $s p$. & 0.30 & 2.90 & 3.01 \\
\hline
\end{tabular}

Table. 5: Growth of Phosphate solubilizing microorganism and in $\mathrm{pH}$ of the Medium due to the

\begin{tabular}{|l|c|c|c|}
\hline \multirow{2}{*}{ Microorganism } & \multicolumn{3}{|c|}{$\mathbf{p H}$} \\
\cline { 2 - 4 } & Second day & Fourth day & Sixth day \\
\hline Uninoculated & 6.87 & 6.84 & 6.84 \\
\hline Bacillus subtilis & 6.51 & 5.20 & 4.96 \\
\hline Micrococcus sp. & 6.74 & 6.41 & 6.40 \\
\hline P. aeruginosa & 6.70 & 6.10 & 6.09 \\
\hline Aspergillus niger & 6.60 & 4.20 & 4.17 \\
\hline Penicillium sp. & 6.79 & 4.70 & 4.42 \\
\hline
\end{tabular}

Table -5 obviously enlightened the effect of $\mathrm{pH}$ and its growth performance of the Phosphate solubilizing microorganism. From this result shows when the treatment days were prolonged and its growth efficiency was reduced according with its $\mathrm{pH}$ level. In addition comparatively inoculate with each respective microorganisms reflected growth efficiency was more in uninoculated condition than the inoculated condition. Though, among the five organisms Penicillium sp., denoted elevated $\mathrm{pH}$ (6.79) for better growth performance reflected only in second day followed by ten fold increased $\mathrm{pH}$ was noted on bacteria $(P$. aeruginosa 6.70$)$ than fungi (A. niger 6.60). However, on sixth day experiment minimum $\mathrm{pH}$ has been noted for very poor growth performance in $A$. niger than remaining organisms. Meanwhile in uninoculated condition fourth and sixth date of observed $\mathrm{pH}$ was constant it was remain unchanged.

Effect of inoculation with phosphate solubilizing microorganism in sterilized and unsterilized condition on Growth performance of spinach leaf. In unsterilized soil condition aerial height was maximum noted in inoculated with $A$. niger $40.3 \pm 1.23$ also other criteria such as number of leaves $(63 \pm 2.06)$, dry weight of the shoot $(0.28 \pm 0.068)$ and total phosphorus $(0.55 \pm 0.01)$ also been maximum noted in an inoculated with B. subtilis. From the research data clearly showed both sterilized and unsterilized condition the significant $\mathrm{p}<0.005 \%$ level of better growth response observed from Inoculated with B. subtilis (Table-6).

Table- 6: Effect of inoculation of phosphate solubilizing microorganism on the growth of spinach (A. cruentus)

\begin{tabular}{|c|c|c|c|c|}
\hline Treatment & $\begin{array}{c}\begin{array}{c}\text { Aerial Height } \\
(\mathrm{cm})\end{array} \\
\end{array}$ & $\begin{array}{c}\text { Number of } \\
\text { leaves }\end{array}$ & $\begin{array}{l}\text { Dry weight of } \\
\text { the shoot }(\mathrm{g})\end{array}$ & $\begin{array}{c}\text { Total phosphorus } \\
(\mathrm{ppm})\end{array}$ \\
\hline \multicolumn{5}{|c|}{ Unsterilized soil } \\
\hline Uninoculated (Control) & $37 \pm 1.11$ & $59 \pm 0.85$ & $0.21 \pm 0.016^{\mathrm{Is}}$ & $0.51 \pm 0.58$ \\
\hline $\begin{array}{l}\text { Inoculated with } \\
\text { B. subtilis }\end{array}$ & $42 \pm 1.25^{*}$ & $63 \pm 2.06 * *$ & $0.28 \pm 0.061 *$ & $0.55 \pm 2.01 * *$ \\
\hline $\begin{array}{l}\text { Inoculated with } \\
\text { A. niger }\end{array}$ & $40.3 \pm 1.02$ & $60 \pm 2.11$ & $0.25 \pm 0.015$ & $0.52 \pm 0.047$ \\
\hline $\begin{array}{l}\text { Inoculated with } \\
\text { Bacillus subtilis and } A \text {. } \\
\text { niger }\end{array}$ & $39.7 \pm 2.85$ & $61 \pm 0.95 *$ & $0.24 \pm 0.026$ & $0.53 \pm 0.065 *$ \\
\hline \multicolumn{5}{|c|}{ Sterilized soil } \\
\hline Uninoculated (Control) & $31 \pm 2.21^{\text {Is }}$ & $46 \pm 0.81$ & $0.15 \pm 0.06$ & $0.49 \pm 0.017$ \\
\hline $\begin{array}{l}\text { Inoculated with } \\
\text { B. subtilis }\end{array}$ & $36.4 \pm 1.25^{* *}$ & $52 \pm 0.31 * *$ & $0.19 \pm 0.06^{*}$ & $0.52 \pm 0.021 * *$ \\
\hline Inoculated & $35.2 \pm 2.30$ & $51 \pm 1.25^{*}$ & $0.18 \pm 0.031$ & $0.50 \pm 0.01$ \\
\hline
\end{tabular}




\begin{tabular}{|l|c|c|c|c|}
\hline A. niger & & & & \\
\hline $\begin{array}{l}\text { Inoculated with } \\
\begin{array}{l}\text { Bacillus subtilis and } A . \\
\text { niger }\end{array}\end{array}$ & $34.8 \pm 0.58$ & $49 \pm 0.73$ & $0.18 \pm 0.095^{\text {Is }}$ & $0.50 \pm 0.02$ \\
\hline
\end{tabular}

$* *_{\text {- indicates the }} \mathrm{p}<0.05 \%$ level of significance

Table- 7: Feasibility Bacillus subtilis and A. niger after every 15 and 30days of Inoculation

\begin{tabular}{|c|c|c|c|c|c|}
\hline \multirow{3}{*}{ Microorganism } & \multirow{3}{*}{$\begin{array}{c}\text { Number of } \\
\text { days }\end{array}$} & \multicolumn{4}{|c|}{ Viable Count (cfu/ml) } \\
\hline & & \multicolumn{2}{|c|}{ Sterilized soil } & \multicolumn{2}{|c|}{ Unsterilized soil } \\
\hline & & $\begin{array}{c}\text { Single } \\
\text { Inoculation }\end{array}$ & $\begin{array}{c}\text { Dual } \\
\text { Inoculation }\end{array}$ & $\begin{array}{c}\text { Single } \\
\text { Inoculation }\end{array}$ & $\begin{array}{c}\text { Dual } \\
\text { Inoculation }\end{array}$ \\
\hline \multirow{2}{*}{ B. subtilis } & 15 & $20 \times 10^{6}$ & $14 \times 10^{6}$ & $22 \times 10^{6}$ & $12 \times 10^{6}$ \\
\hline & 30 & $56 \times 10^{6}$ & $30 \times 10^{6}$ & $53 \times 10^{6}$ & $22 \times 10^{6}$ \\
\hline \multirow{2}{*}{ A. niger } & 15 & $3.2 \times 10^{4}$ & $2.5 \times 10^{4}$ & $5.6 \times 10^{4}$ & $2 \times 10^{4}$ \\
\hline & 30 & $8 \times 10^{4}$ & $3 \times 10^{4}$ & $5.8 \times 10^{4}$ & $2.4 \times 10^{4}$ \\
\hline
\end{tabular}

Table-7 confirmed that growth effect of spinach (A. cruentus) following criteria such as showed the activity of bacterial and fungal forms, including Bacillus, and Aspergillus, as phosphate solubilizers. The PSMs with the most phosphate-solubilizing ability was Bacillus among the bacterial and Aspergillus among the fungal isolates. The results indicated greater numbers of microorganisms showing the maximum zone of clearance of phosphates on the medium. The count of Bacillus species in the sterilized condition cfu count was much higher than the counts of the rhizospheric fungi. In sterilized soil fifteen and thirty days experiment PSF count ranged from 2.5 to $3.210^{4} \mathrm{cfu} / \mathrm{ml}$ and $3 \times 10^{4}$ to $8 \times 10^{4}$ at single and dual inoculation. Despite in unsterilized condition the PSF were much higher than the counts of the sterilized rhizospheres soil (Table-7).

The Fig.: 1 showed titrable acidity of five phosphate solubilizing microorganism with uninoculated and inoculated condition at second, fourth and fifth date of treatment. The result revealed that dominant titrable acidity has been observed on sixth day experiment from Fungi of A. niger. Mean time on fourth day of the experiment another peak titrable activity was noted in similar fungi followed by Penicillium sp., too. However, no other remarkable variation has been noted in titrable acidity with uninoculated condition.

Irrespectively depends upon the temperature minimum and maximum range of $\mathrm{pH}$ level observed in A. niger and $B$. subtilis respectively. Interestingly suddenly attained peak level of notable $\mathrm{pH}$ was 3 this value being same on both organisms of the fungi and bacteria at $28^{\circ} \mathrm{C}$. Similar results also been obtained at $37^{\circ} \mathrm{C}$ too (Fig-2 and 3).

Fig-1: Alteration of Titrable Acidity of the Medium due in the growth of phosphate solubilizing microorganism

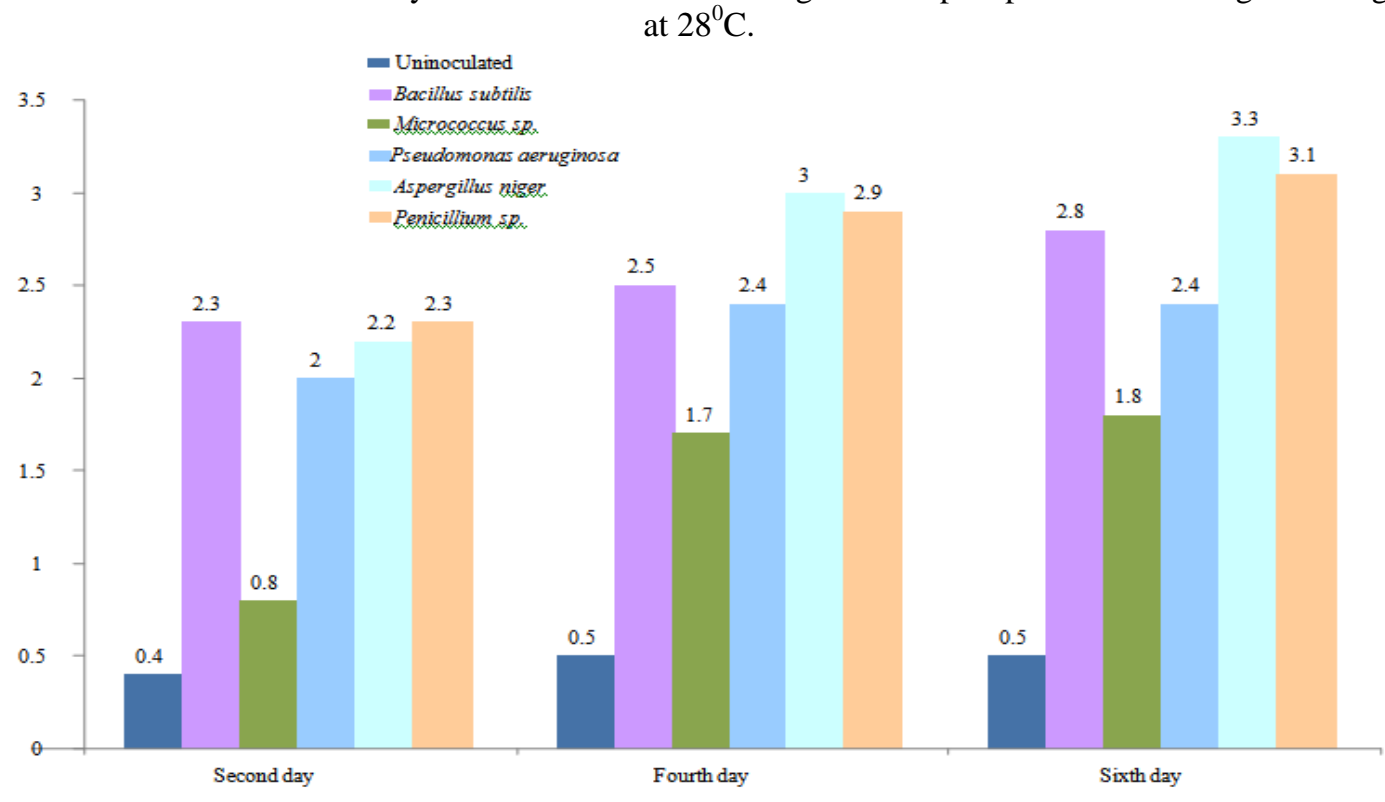


Fig-2: Effect of $\mathrm{pH}$ on tricalcium phosphate solubilization by $B$. subtilis and A. niger at $28^{\circ} \mathrm{C}$

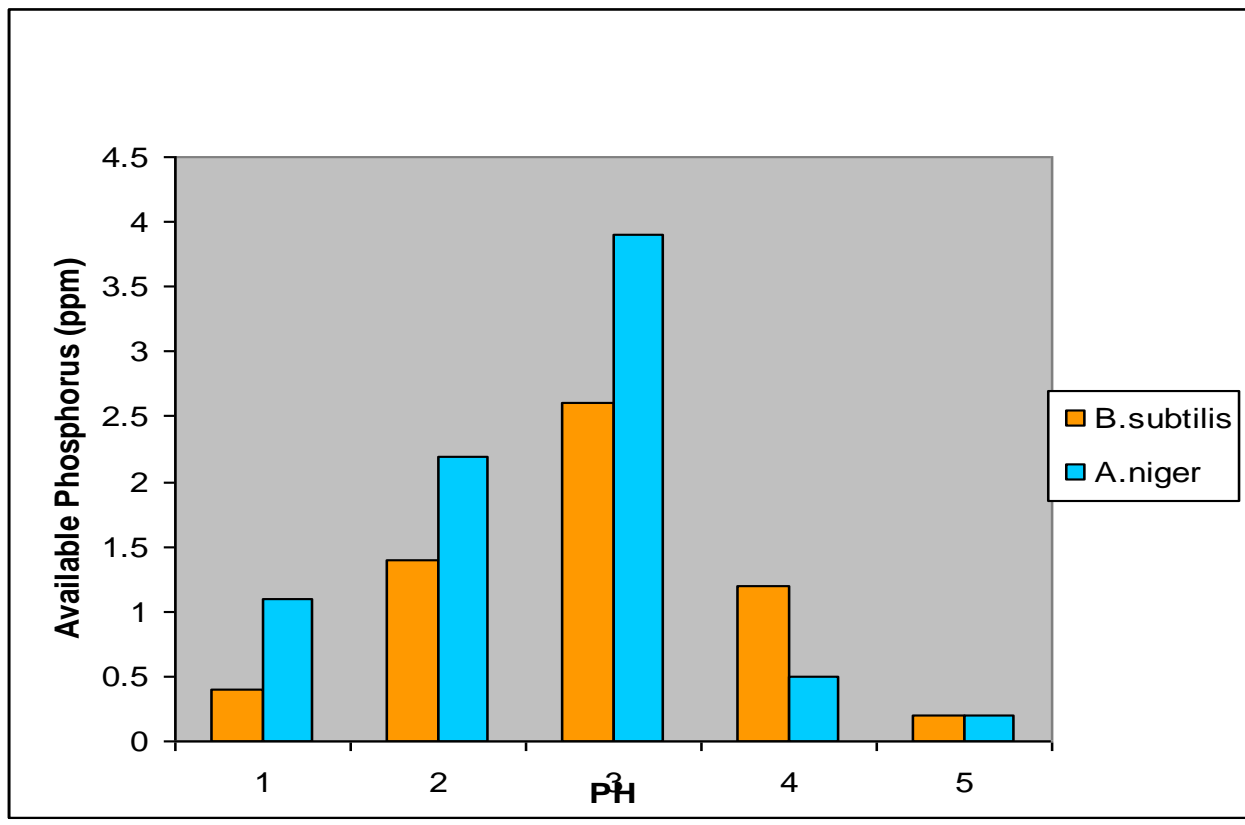

Fig- 3: Effect of pH on tricalcium phosphate solubilization by

B.

subtilis

and A. niger at $37^{\circ} \mathrm{C}$

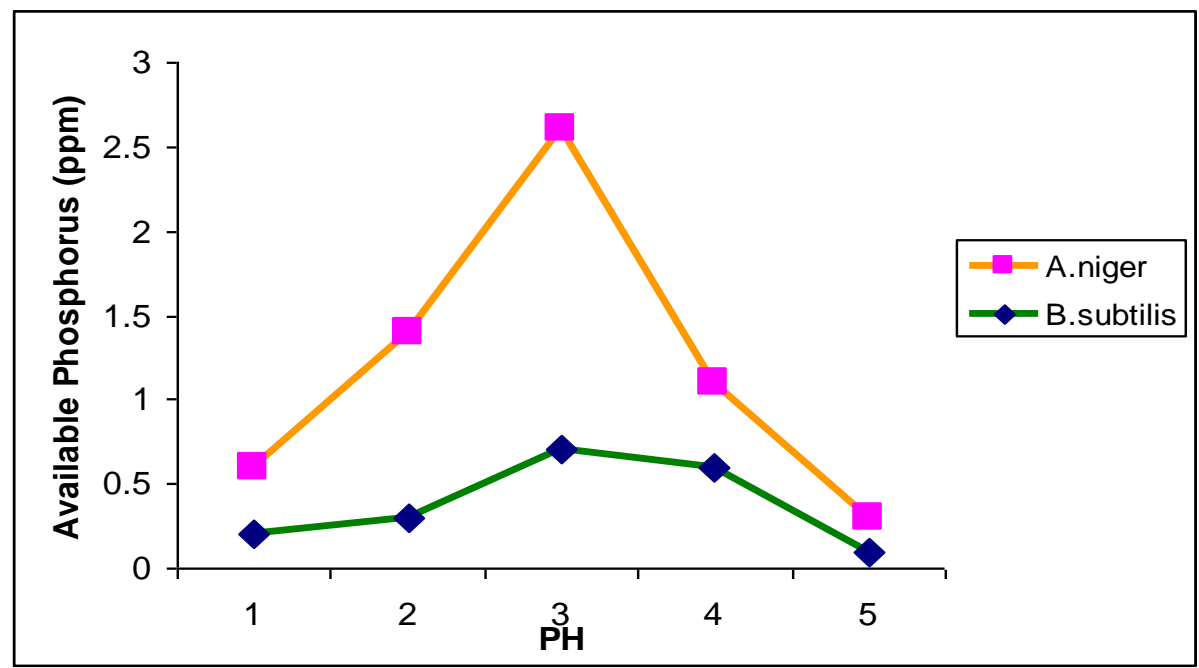

\section{Discussion}

Phosphorus is one of the most essential elements for the growth and development of plants. Phosphorus exists in soil as phosphate anions and these phosphate anions are extremely reactive and are immobilized by soil cations and thus make it unavailable for plants. There are certain microorganisms that are capable of solubilizing the unavailable form of phosphorus into available form (Hilda and Fraga, 1999). Such microorganisms are called phosphate solubilizing microorganisms. It is therefore necessary to isolate and identify potent phosphate solubilizers. In the present study phosphate solubilizing microorganisms were isolated from the rhizosphere soil of banana plants by serial dilution and plating on Pikovskaya's Agar medium. Three bacterial species and two fungal species were found to solubilizing tri calcium phosphate supplemented in the media. The bacterial species were identified as Bacillus subtilis, Pseudomonas aeruginosa and Micrococcus sp. This finding is supported by an earlier report that says that most efficient and frequently encountered phosphate solubilizing bacteria belonging to the genus Pseudomonas or the genus Bacillus (Sundaram, 1994). Venkateswaran and Natarajan (1983) reported Pseudomonas sp. and Bacillus sp. as dominant inorganic phosphorus compounds solubilizing microbes. The fungal isolates capable of solubilizing the phosphate present in the media were identified as Aspergillus niger and Penicillium sp. These findings also correlate with the findings of Nahas et 
al., (1990) who suggested that A.niger is a well-known phosphate solubilizing fungi. Penicillium sp. was also identified as efficient phosphate solubilizer.

The P-solubilizing activity is determined by the microbial biochemical ability to produce and release organic acids, which through their carboxylic groups chelate the cations (mainly Ca) bound to phosphate converting them into the soluble forms (Kpomblekou and Tabatabai, 1994; Glick, 1995). From the results of this study, it is being reaffirmed that the phosphate solubilization by different PSBs is involved with the production of organic acids (Fasim et al., 2002; Rashid et al., 2004).

Phosphorus is an abundant in several soils and is one of the major nutrients limiting the plant growth. The overall $\mathrm{P}$ use efficiency following phosphate fertilizer application is low because of the formation of insoluble complexes (Vassilev and Vassileva, 2003). Hence, frequent application of soluble forms of inorganic$\mathrm{P}$ is necessary for crop production and which leaches to the ground water and results in eutrophication of aquatic systems (Del Campillo et al., 1999; Hilda and Fraga, 1999). In view of environmental concerns and current developments in sustainability, research efforts are concentrated on elaboration of techniques that involve the use of less expensive, though less bio-available sources of plant nutrients such as rock phosphate and by application of PSB the agronomic effectiveness can be enhanced (Whitelaw, 2000).

However, conversed result reported that Aspergillus niger has higher solubilization index than Penicillium Krishnaraj et al., 1999. While, this kind of comparable results have been reported by many investigators (Afzal et al., 2005; Gupta et al., 2007).

Higher the value of Solubilization Efficiency (SE) the greater the activity of the tested isolate was. But with that method it could not be able to quantify the amount of phosphate solubilized at the end of incubation time. So, liquid culture experiments were performed to evaluate the amount of phosphate solubilized. Liquid media inoculated with A. niger released more available phosphate and B. subtilis ranked second. Deubel and Merbach (2005) tested eight strains on calcium phosphate agar plates and found out that only two of them showed clear zone around their colony and would be identified as phosphate solubilizers. Moreover, it was noted that the best strain in solubilizing the same phosphate source in liquid media was one of the strains which could not show clear zone on agar plates.

The current study also evidenced that the liquid media inoculated with phosphate solubilizing microorganisms is accompanied by a reduction in $\mathrm{pH}$. A. niger, among fungal isolates and Bacillus subtilis among bacterial isolates showed greater reduction in $\mathrm{pH}$ when inoculated in liquid medium. Hence it is found that more the phosphate solubilizes greater is the reduction in $\mathrm{pH}$. Hence the isolates were found to produce carboxylic acids to solubilize the phosphate in the medium. This agrees with the test results of many investigators (Ryan et al., 2001). The titrable acidity was also determined to confirm the release of carboxylic acid in the medium. The converse correlation observed between the $\mathrm{pH}$ and soluble-P concentration indicates that organic acid production by these PSB strains plays a significant role in the acidification of the medium facilitating the $\mathrm{P}$ solubilization. Similar inverse relationship between $\mathrm{pH}$ and soluble phosphate was reported earlier by Hwangbo et al. (2003).

\section{Conclusion}

The results showed that the seedling inoculated with Bacillus subtilis had bigger aerial height, dry weight and number of leaves also it has been more available phosphorus when compared to other treatments. Invitro results showed A. niger has greater phosphate solubilization efficiency than Bacillus subtilis. But the results do not match with the field trials. This may be due to the fact that the soil conditions favored the growth of $B$. subtilis. And also from the results it is seen that combined treatment of both bacteria and fungi showed decreased vegetative growth rate when compared to single inoculation, and the population density of $B$. subtilis is higher in the combined treatment than the fungal density. It predicts the $B$. subtilis may have an antagonistic effect

A. niger. It was concluded from the present study that all the PSB isolates except three produced multiple organic acids followed by a decrease in the $\mathrm{pH}$ of the culture medium there by solubilizing the insoluble tricalcium phosphate. More studies are defensible to understand the significance and mechanism used by an unidentified acid1 in MPS activity. Use of these PSB as bioinoculants will increase the available P in soil, helps to minimize the P-fertilizer application, reduces environmental pollution and promotes sustainable agriculture. So far, the application of phosphate-solubilizing bacteria in most examined traits was better than chemical fertilizer.Moreover,theinoculationwith $B$. subtilis and $A$. niger most examined traits has significant difference with uninoculated condition. So the impact of phosphate solubilizing on examined traits was more than inoculation with B. subtilis and A. niger.

\section{Acknowledgement}

We would like to acknowledge to the HOD of the Department of Microbiology in Malankara Catholic College for providing the necessary fascilities for completion of this work. Also the first as well as 
corresponding author expressed the gratitude to Correspondent and Secretary of Rev.Fr. Premkumar, MSW., has given the constant encouragement for preparing this work for publication.

\section{References}

[1] Jedidi, N., A. Hassen, O. Van Cleemput and A. M' Hiri, 2004. Microbial biomass in a soil amended with different types of organic wastes.WasteManage.Res.,22:93-99. Abdalla, M.H. and Omar, S.A. (2001). Survival of Rhizobial Bradyrhizobia and a rock phosphate solubilizing fungus Aspergillus niger on various carriers from some agroindustrial wastes and their effect on nodulation and growth of fababean and soyabean. J. Plant. Nut. 24: 261-271.

[2] Afzal, A., Ashraf, M., Asad, A.S. and Farooq, M. (2005). Effect of phosphate solubilizing microorganisms on phosphorus uptake, yield, and yield traits of wheat (Tritium aestivum) in rain fed area. Int. J. Agri. Biol. 7 (2): 207-209.

[3] Afzal, A. and Ashgari, B. (2008). Rhizobium and Phosphate Solubilizing bacteria improve the Yield and Phosphorus Uptake in Wheat (Triticum aestivum). Int. J. Agri. Biol. 10(1): 85-88.

[4] Chen, Y.P., Rekha, P.D., Arun, A.B., Shen, F.T., Lai, W.A. and Young, C.C. (2006). Phosphate solubilizing Bacteria from subtropical soil and their tricalcium phosphate solubilizing abilities. Appl. Soil. Ecol. 34: 33-41.

[5] De Souza, M.J.B.D., Nair, S. and Chandramohan, D. (2000). Phosphate solubilizing bacteria around Indian Peninsula. Indian Journal of Marine Sciences. 29: 48-51.

[6] Deubel, A. and Merbach, W. (2005). Influence of microorganisms on phosphorus bioavailability in soils. In: buscot F, varma A (Eds.), microorganisms in soils: roles in Genesis and functions. Springer, Berlin Heidelberg, pp: 177-191.

[7] Del Campillo, S.E., Van der Zee, S.E.A.T.M., Torrent, J., 1999. Modelling long-term phosphorous leaching and changes in phosphorous fertility in selectively fertilized acid sandy soils. Eur. J. Soil Sci. 50, 391-399.

[8] Fasim, F., Ahmed, N., Parson, R., Gadd, G.M., 2002. Solubilization of zinc salts by a bacterium isolated from air environment of a tannery. FEMS Microbiol. Lett. 213, 1-6.

[9] Glick, B.R., 1995. The enhancement of plant growth by free-living bacteria. Can J. Microbiol. 41, 109-117.

[10] Hilda, R., Fraga, R., 1999. Phosphate solubilizing bacteria and their role in plant growth promotion. BiotechnoL, Adv. 17, 319-359.

[11] Hwangbo, H., Park, R.D., Kim, Y.W., Rim, Y.S., Park, K.H., Kim, T.H., Suh, J.S., Kim, K.Y., 2003. 2-Ketogluconic production and phosphate solubilization by Enterobacter intermedium. Curr. Microbiol, 47, 87-92.

[12] Kpomblekou, K., Tabatabai, M.A., 1994. Effect of organic acids on release of phosphorus from phosphate rocks. Soil Sci. 158, 442453.

[13] Rashid, M., Khalil, S., Ayub, N., Alam, S., Latif, F., 2004. Organic acids production and phosphate solubilization by phosphate solubilizing microorganisms (PSM) under in vitro conditions. Pak. J.Biol. Sci. 7, 187-196.

[14] Vassilev, N., Vassileva, M., 2003. Biotechnological solubilization of rock phosphate on media containing agro-industrial wastes. Appl. Microbiol. Biotechnol. 61, 435-440.

[15] Fankem, H., Dieudonne Nwaga, Annette Deubel, Wolfgang Merbach and Francois Xavier Etoa. (2006). Occurence and functioning of phosphate solubilizing Microorganisms from oil palm tree (Elaeis guineensis) rhizosphere in Cameroon. African Journal of Biotechnology, 5(24): 2450-2460.

[16] Ryan, P.R., Delbaise, E. and Jones, D.L. (2001). Function and Mechanism of organic anion exudation from plant root. Ann. Rev. Plant Physiol. Plant mol. Biol. 52:527-560.

[17] Nopparat, C., Jatupornpilat, M. and Rittiboon,A. (2007).Isolation of phosphate solubilizing fungi in soil from Kanchnaburi, Thailand. KMITL Sci.Tech. J. 7:137-146.

[18] Gupta N, Sabat J, Parida R 2007. Solubilization of tricalcium phosphate and rock phosphate by microbes isolated from chromite, iron and manganese mines. Acta Bot Croat, 66: 197-204. 